\title{
Preface for special issue on the occasion of José H. Zagal 70th birthday
}

\author{
Maritza Angélica Páez ${ }^{1}$
}

Received: 26 May 2020 / Revised: 26 May 2020 / Accepted: 27 May 2020 / Published online: 9 June 2020

(C) Springer-Verlag GmbH Germany, part of Springer Nature 2020

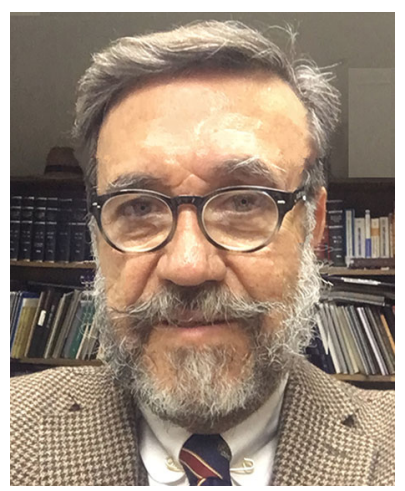

José H. Zagal is a Distinguished Professor at the Faculty of Chemistry and Biology of the University of Santiago de Chile and directs the Laboratory of Electrocatalysis. He got his first degree in chemistry from the University of Chile and his Ph.D. from Case Western Reserve University in 1978. He was a postdoctoral fellow at Brookhaven National Laboratory in 1982. His research interests are in fundamental studies of electrochemical and electrocatalytic processes through a combination of experimental and some theoretical investigations. He has conducted pioneering studies on establishing reactivity descriptors and volcano correlations for non-precious metal $\mathrm{M}-\mathrm{Nx}$ and $\mathrm{MN}_{4}$ molecular catalysts covering not only fuel cell reactions like oxygen reduction, but also many other electrochemical processes involving the oxidation of small molecules and other species of biological relevance. He has also introduced the concept of donor-acceptor intermolecular hardness to explain the reactivity trends of MN4 molecular catalysts in electrochemical reactions in general. He has also contributed to the field of conductive polymers, sensors modified electrodes, self-assembled molecular catalysts, molecular electronics, and corrosion. He was awarded the Presidential Chair in Science in 1996 by a Committee chaired

Maritza Angélica Páez

maritza.paez@usach.cl

1 Departamento de Química de los Materiales, Facultad de Química y Biología, Universidad de Santiago de Chile, Santiago, R.M., Chile by Chemistry Nobel Laureate Rudolph A. Marcus. He has also received several other Chilean awards. In 2014, he was elected Fellow of the International Society of Electrochemistry (ISE) and became a Fellow of The Electrochemical Society (ECS) in the same year. He was admitted to the Academy of Sciences of Latin America (ACAL) in 2018. The same year, he was awarded the Fellow category of the Royal Society of Chemistry (RCS) and was appointed Emeritus Member of ECS. At present, he is ViceChair of the Molecular Electrochemistry Division of ISE. He is President and founder of the Chilean Association of Carbonaceous Materials and was elected President of the Iberoamerican Society of Electrochemistry (SIBAE) (20192020). He was a member of the Superior Council of Science and Technology appointed by the President of Chile for the period 2011-2013

He has published over 250 papers and 9 book chapters, coauthored and edited 5 books, and has been awarded 3 patents. He has delivered more than 400 papers at national and international meetings worldwide and presented plenary conferences. He has served in the Editorial Boards for J. Appl. Electrochem. (19882010), J. Chil. Chem. Soc. (1984-2007), and Electrocatalysis (2009-2015). He is presently a member of the Editorial Boards of J. Solid State Electrochem., Electrochem. Comm., Internat. J. Electrochem., J. Serbian Chemical Soc., Frontier in ChemistryElectrochemistry, Applied Surface Science, Current Electrocatalysis, and Chimica Nova. He has been a Guest Editor of Special Issues in the International Journal of Electrochemistry, Journal of Applied Electrochemistry, Current Opinion in Electrochemistry, and Molecules. He has trained many students, many of whom are now with permanent academic positions: he has supervised 30 graduate theses and 36 professional theses and has mentored 23 postdocs. He was the Chairman of the Chemistry Department and Director of the Doctoral Program in Chemistry and helped to create the first doctoral program at the University of Santiago de Chile.

Maritza A. Paez

Guest Editor 